\title{
Construindo a "nação brasiliense": Poderes Locais e Identidades Políticas na Bahia, (1815-1831)
}

Constructing the "brasiliense nation": Local Government and Political Identities in the Bahia, (1815-1831)

Maria Aparecida Silva de Sousa

Doutoranda FFLCH/USP

\begin{abstract}
Resumo
A pesquisa discute como as mudanças politicas decorrentes da crise do Império luso-brasileiro interferiram nos ajustamentos internos da capitania e posterior província da Bahia, no período de 1815-1831. Parte da proposição que a percepção diferenciada dos acontecimentos pelos protagonistas resultou na diversidade de projetos de futuro conformando um cenário de intensas negociações e conflitos como expressões das identidades políticas em gestação. Especificamente, analisa a tessitura dos poderes locais, em especial a atuação das câmaras municipais, atentando para a sua inserção na complexa trama dos interesses que marcou a construção do Império do Brasil numa situação particular.
\end{abstract}

\begin{abstract}
The research argues as the changes decurrent of the crisis of the Empire luso-Brazilian interfered in the internal adjustments in the Bahia, from 1815 to 1831. It suggests that the differentiated perception of the events for the protagonists resulted in the diversity of future projects conforming a scene of intense negotiations and conflicts as expressions of the political identities in gestation. Specifically, analyze the tessitura of local government, in special the performance of the councils, attempting against for its insertion in the complex tram of the interests that marked the construction of the Empire of Brazil in a particular situation.
\end{abstract}

\section{Palavras-chave}

Bahia, câmaras municipais, identidade nacional, Império do Brasil.

\section{Keywords}

Bahia, municipal councils, national identity, Brazilian Empire. 
JANCSÓ, István. (Org.). Brasil: formação do Estado e da Nação. São Paulo: Hucitec; Ed. Unijuí; Fapesp, 2003.

MATTOSO, Kátia M. de Queirós. Bahia, século XIX: uma provincia no império. 2. ed. Rio de Janeiro: Nova Fronteira, 1992, especialmente 0 livro IV; WISIAK, Thomas. A 'Nação partida ao meio': tendências políticas na Bahia na crise do Império luso-brasileiro. Dissertação (Mestrado em História) - Universidade de São Paulo, São Paulo, 2001; GUERRA FILHO, Sérgio Armando Diniz. 0 povo e a guerra. Participação das camadas populares nas lutas pela Independência da Bahia. Dissertação (Mestrado em História) Universidade Federal da Bahia, Salvador, 2004. 3

SOUZA FILHO, Argemiro Ribeiro de. A guerra de Independência na Bahia: manifestações politicas e violência na formação do Estado Nacional (Rio de Contas e Caetité). Dissertação (Mestrado em História) - Universidade Federal da Bahia, Salvador, 2003; NEVES, Erivaldo Fagundes. Posseiros, rendeiros e proprietários: Estrutura fundiária e dinâmica agro-mercantil no Alto Sertão da Bahia (1750-1850). Tese (Doutorado em História) - Universidade Federal de Pernambuco, Recife, 2003.

JANCSÓ, István, op. cit.
Nos últimos anos, os estudos sobre a desagregação do Antigo Regime na América portuguesa têm tido consideráveis avanços. Na esteira de um debate mais amplo sobre a questão nacional, revigorado pelos acontecimentos mundiais das últimas décadas do século XX, essas investigações, com base em novas proposições teóricas e metodológicas, possibilitam revelar os intricados nexos dos diferentes projetos políticos que envolveram a emergência do Estado e da nação brasileiros, ampliando abordagens clássicas da historiografia sobre o tema. ${ }^{1}$

0 aprofundamento das pesquisas permite a formulação de novas questões e o delineamento de recortes temáticos mais precisos. No caso específico da Bahia, não obstante a qualidade dos estudos sobre o século $\mathrm{XIX}$, as pesquisas que abordem o universo das relações politicas locais na transição colônia/império são quase inexistentes. ${ }^{2}$ Esta constatação é ainda mais evidente quando levamos em consideração as áreas externas à capital e ao Recôncavo baianos, salvo algumas exceções. ${ }^{3}$ Esta lacuna historiográfica remete para a necessidade de redimensionamento das articulações estruturais recuperando o papel da capitania e posterior província da Bahia nos quadros do Antigo Regime, e da sua configuração sócio-política no período pós-independência o que, de resto, envolve um longo caminho a ser percorrido pelo historiador interessado na compreensão da gênese do Estado nacional.

A pesquisa agora apresentada propõe discutir as mudanças políticas decorrentes da atribuição ao Brasil da condição de Reino, em dezembro de 1815, e sua interferência sobre os ajustamentos internos da Bahia ante as expectativas abertas pelo impacto dessa medida. Como já foi proposto, as percepções diferenciadas da crise em curso resultaram em considerável diversidade de projetos sinalizando o esgotamento de formas de ordenamento político desdobradas em novas ações e propostas alternativas de futuro. ${ }^{4} 0$ aprofundamento da crise, em decorrência do movimento vintista, recrudesceu os conflitos entre as partes constitutivas do Reino, conferindo visibilidade a projetos políticos incompativeis capitaneados pelas autoridades locais/regionais.

Na direção proposta por esta investigação, a abordagem da dinâmica política da Bahia nas primeiras décadas do oitocentos recupera as câmaras municipais como organismos privilegiados de ressonância dos acontecimentos políticos naquela conturbada conjuntura. A rigor, será por meio dos órgãos camarários que os "homens da governança" articularam negociações políticas de maior abrangência.

Todavia, discutir as dinâmicas locais exige o acompanhamento da ampla rede de negociação institucional configurada nos espaços de representação e de dominação na capitania/província, tanto porque é nesse âmbito que ganham clareza as disputas internas revelando a questão das autonomias regionais e as respectivas competências políticas, indicadoras do intricado jogo de interesses que certamente não se esgotam nos limites das fronteiras provinciais. Além disso, os primeiros anos da década de 1820 foram particularmente efervescentes na Bahia não apenas em virtude da guerra civil iniciada em junho de 1822, mas também pela dimensão das tensões políticas que ultrapassaram o término do conflito.

A análise de documentos existentes nos arquivos baianos (Arquivo Público do Estado da Bahia, Arquivo Histórico Municipal de Salvador, IGHB, Arquivo Municipal de Rio de Contas, Arquivo Municipal de Cacho- 
BOXER, Charles R. 0 império colonial português (1415-1825). Lisboa: Edições 70, 1981; RUSSELLWOOD, A. J. R. 0 governo local na América portuguesa: um estudo de divergência cultural. Revista de História, São Paulo, v. LV, ano XXVIII, 1977, p. 25-79; SCHWARTZ, Stuart B. Burocracia e sociedade no Brasil colonial. São Paulo: Perspectiva, 1979.

Com diferentes visões sobre a extensão de poderes e atribuições das câmaras municipais no período colonial. Para Oliveira Vianna, por exemplo, as instituições camarárias se caracterizavam pela ausência de participação política do povo, resultando em "corporações de tipo oligárquico e aristocratizado" (Cf. Instituições políticas brasileiras. Belo Horizonte: Itatiaia; São Paulo: EDUSP; Niterói: EDUFF, v. 1, 1987, p. 114); Caio Prado Junior destaca a subordinação das câmaras ao governo geral, porém adverte que assumiam um papel importante em razão da "forma popular que se constituem e funcionam" intervindo decisivamente "nos sucessos da constitucionalização, independência e fundação do Império" (Cf. Formação do Brasil contemporâneo. 22. ed. São Paulo: Brasiliense, 1992, p. 319); Raymundo Faoro, por sua vez, contesta qualquer vitalidade das câmaras pois, para ele, nunca passaram de corporações administrativas, se convertendo, na prática "em simples executoras de ordens superiores". De acordo essa perspectiva, a lei imperial de $1^{\circ}$ de outubro de 1828 ao subordinar as câmaras ao governo provincial e geral, apenas certificou uma prática tradicional, "apesar do renascimento primaveril nos dias da Independência" (Cf. Os donos do poder. Formação do patronato político brasileiro. 10. ed. São Paulo: Globo, v. 1, 1996, p. 187 e 187). Outros estudos sobre a administração colonial na América Portuguesa podem ser vistos em: SALGADO, Graça (Coord.). Fiscais e meirinhos. A administração no Brasil colonial. Rio de Janeiro: Nova Fronteira, 1985; WEHLING, Arno. A administração portuguesa no Brasil: 1777-1808. Brasilia: Funcep, 1986; Anais do I Colóquio de Estudos Históricos Brasil-Portugal. Belo Horizonte: PUCl Minas Gerais, 1994.

7

Para uma amostra dessa produção acadêmica, ver: VIEIRA, Alberto (Org.). O município no mundo português. Seminário Internacional. Funchal: CEHA; Secretaria Regional do Turismo e da Cultura, 1998.

Cf. MONTEIRO, Nuno Gonçalo. Poderes municipais e elites locais (séculos XVII-XIX): Estado de uma questão. In: VIEIRA, Alberto, op. cit., p. 79. Alguns estudos sobre a América Portuguesa têm identificado um canal latente de comunicação entre os colonos e o monarca português que ultrapassava os degraus hierárquicos da burocracia administrativa colonial. BICALHO, Maria Fernanda, 2003, op. cit.; As câmaras municipais no Império português. Revista Brasileira de História. São Paulo, Anpuh; Humanitas Publicações, v. 18, n. 36, 1998, p. 251-280; MELLO, Evaldo Cabral de. A fronda dos mazombos. Nobres contra mascates, Pernambuco, 1666-1715. 2 ed. São Paulo: Editoria 34, 2003; RUSSEL-WOOD, A. J. R., op. cit.; Sérgio Buarque de Holanda já havia assinalado a correspondência entre as capitanias e a metrópole: "Na prática, e não obstante os dizeres dos decretos de eira) bem como nos acervos do Arquivo Nacional e da Biblioteca Nacional do Rio de Janeiro, e cujo levantamento já teve início, permitirá conferir consistência às investigações.

Num primeiro momento, pretende-se explorar a vasta documentação produzida pelos órgãos camarários da Bahia, a exemplo da correspondência mantida com as autoridades da administração geral, judiciária e militar; em seguida focalizar as fontes documentais que evidenciem as articulações locais com outras esferas do poder central, em busca da apreensão das práticas políticas dos grupos dirigentes, possibilitando identificar a inserção da província no processo de emergência do Estado e da Nação brasileiros. A investigação parte da hipótese que a construção da unidade nacional, na Bahia, se deu em meio a intensos conflitos, negociações e rompimentos entre as forças políticas locais, configurando um complexo jogo de alianças no qual os grupos dirigentes buscaram assegurar interesses políticos e econômicos no processo de acomodação da província baiana no contexto de ruptura luso-brasileira.

\section{Senado da Câmara: do regime colonial ao Estado imperial}

0 estudo da instituição camarária como pilar do Império português remonta a Boxer e foi ampliado pelas investigações de John Russel-Wood e Stuart Schwartz, revelando que as câmaras ocuparam um lugar de destaque na estrutura politico-administrativa da Monarquia não somente como "complexa máquina de controle" no Brasil, também nas demais possessões africanas e asiáticas. A despeito das especificidades das regiões conquistadas, o fato é que as linhas estruturantes dos concelhos foram introduzidas como sistema governativo nos espaços de além-mar, constituindo um poderoso instrumento de interlocução das populações locais com o poder central, e de intervenção dele na sociedade colonial. 5

Não obstante a historiografia brasileira ter produzido estudos relevantes sobre a estrutura político-administrativa do Brasil colonial e sua vinculação com os processos econômicos e sociais ${ }^{6}$, abordagens mais pontuais sobre a história dos municipios, do poder local e dos grupos dirigentes ainda figuram de maneira tímida no campo da produção acadêmica. Percorrendo um caminho inverso, em Portugal tem-se verificado nos últimos anos uma renovação historiográfica sobre as organizações políticas locais, e as suas vicissitudes, sobretudo para o periodo de vigência da Monarquia. ${ }^{7}$ Na avaliação de Nuno Gonçalo Monteiro, essas pesquisas têm proporcionado a revisão da "precoce atrofia dos poderes municipais subjugados pelo peso da centralização absolutista" proporcionando a redescoberta da "sua vitalidade e das respectivas elites até as grandes reformas da revolução liberal triunfante (1832-1836)".8

A fundação de vilas ou cidades no Brasil Colônia implicava na instalação da câmara municipal responsável pelo desempenho de funções político-administrativas, judiciais, fazendárias e de polícia. A organização do governo e da administração local pautava-se pelas mesmas leis metropolitanas que, entre outras regulamentações, determinava a escolha dos representantes do poder camarário entre os "homens bons" da urbe, aqueles indivíduos revestidos da condição nobiliárquica e que possuissem bens de raiz. Mesmo considerando diferenças de riqueza, parece evidente que os homens aptos a ocupar os "cargos da governança" possuiam determinados atributos que os distinguiam dos demais habitantes das municipalidades. Ainda assim, é preciso levar em consideração a profunda 
nomeação e dos regimentos, o poder lato que se conferia aos vice-reis, subordinando-Ihes todos os funcionários e oficiais do Estado, permanecia letra morta". Cf. HOLANDA, S. Buarque. A herança colonial - sua desagregação. In:____ (Dir.). História geral da civilização brasileira. 0 Brasil Monárquico. São Paulo: Difel, 1985, t. II, v. I, p. 22

Pesquisando sobre a composição das elites locais dos municípios portugueses na passagem do século XVIII para o XIX, Nuno Gonçalo Monteiro aponta para as distinções de níveis de riqueza e de nobreza entre as elites da corte e das províncias e mesmo no interior destas regiões. Cf. MONTEIRO, Nuno Gonçalo, op. cit., p. 79-90.

10

Cf. GOUVÊA, Maria de Fátima Silva. Redes de poder na América portuguesa. 0 caso dos homens bons do Rio de Janeiro, 1790-1822. Revista Brasileira de História, São Paulo, Anpuh/Humanitas Publicações, v. 18, n. 36,1998 , p. 297-330 e da mesma autora: Poder político e administração na formação do complexo atlântico português (1645-1808). In: FRAGOSO, J., BICALHO, M. F.; GOUVÊA, M. F. $O$ antigo regime nos trópicos: a dinâmica imperial portuguesa (séculos XVI-XVIII). Rio de Janeiro: Civilização Brasileira, 2001. p. 285-315; As bases institucionais da construção da unidade. Administração e governabilidade no período joanino (1808-1821). Texto apresentado no Seminário Internacional Independência do Brasil: História e Historiografia, São Paulo, USP, 2003 (no prelo); LEITE, Renato. Câmaras das cidades do Rio de Janeiro e de Recife à época da Independência do Brasil 1822-1824. In: VIEIRA, Alberto, op. cit., p. 483-490; SOUZA, lara Lis Carvalho. A adesão das câmaras e a figura do imperador. Revista Brasileira de História, São Paulo, Anpuh/Humanitas Publicações, v. 18, n. 36, 1998, p. 367-394;

BICALHO, Maria Fernanda. A cidade e o império. 0 Rio de Janeiro no século XVIII. Rio de Janeiro: Civilização Brasileira, 2003 e da mesma autora: As representações da Câmara do Rio de Janeiro ao monarca e as demonstrações de lealdade dos súditos coloniais, séculos XVII-XVIII. In: VIEIRA, Alberto, op. cit., p. 523-543.

11

Para uma análise sobre a importância políticoeconômica que o Rio de Janeiro adquiriu desde a segunda metade do século XVIII, ver BICALHO Maria Fernanda, 2003, op. cit; FRAGOSO, João Luis R. Homens de grossa ventura: acumulação e hierarquia na praça mercantil do Rio de Janeiro (1790-1830). Rio de Janeiro: Arquivo Nacional, 1992; DIAS, Maria Odila da Silva. A interiorização da Metrópole. In: MOTA, Carlos Guilherme (Org.). 1822 Dimensões. São Paulo: perspectiva, 1972; OLIVEIRA, Cecilia Helena de S. A astúcia liberal: Relações de mercado e projetos politicos no Rio de Janeiro (1820-1824). Bragança Paulista: Edusf; Ícone, 1999.

\section{2}

Para o caso de Salvador, por exemplo, é possive que ao longo do século XVIII, o domínio exclusivo dos senhores de engenho no senado da câmara tenha sido ameaçado em função da crescente afirmação política dos comerciantes. As diferenças econômicas predominantes no interior da capitania com a proeminência de proprietários de terra, gado e escravos pode ter influído na caracterização dos "homens bons", o que aponta para uma investigação mais ampliada sobre o tema. diversidade econômica, espacial, populacional entre as várias regiões integrantes da América Portuguesa e depois Império do Brasil que certamente influía na caracterização dos grupos dirigentes locais, indicando maior prudência na definição da categoria de "elites". ${ }^{9}$

No que se refere à temática especifica das câmaras municipais na crise do Império português na América, boa parte dos estudos tem se centrado sobre a região Centro-Sul e sua dinâmica própria. ${ }^{10}$ De fato, essas abordagens vinculam-se a uma compreensão da crescente importância do Rio de Janeiro como foco de articulação da região a partir do periodo pombalino, cuja importância foi potencializada com a erosão do Antigo Sistema Colonial. ${ }^{11}$ Não resta dúvidas que as questões suscitadas pelas pesquisas têm propiciado uma releitura das relações coloniais como também sobre os ajustamentos internos possibilitados pelo aprofundamento da crise. ${ }^{12}$

Maria de Fátima Gouvêa observa que a análise das listas nominais dos vereadores do Rio de Janeiro entre os anos de 1790-1822 indica uma mudança no perfil dos ocupantes dos cargos camarários. Segundo afirma, em fins do XVIII, aparecem como negociantes, pouco se referindo às suas relações de parentesco, diferentemente de 1822 quando "se apresentavam sob o signo dos títulos honoríficos e das relações familiares que os uniam. A imagem que se queria passar parecia ser aquela de uma sólida familia, unida pelos valores da distinção social [...], assim como pelo sentimento promovido pelo pacto estabelecido entre a Coroa - agora já brasileira - e os seus nobres súditos".13

Gouvêa acredita que essa metamorfose social se relaciona com o impacto causado no senado da Câmara pela elevação do Brasil à condição de Reino. 0 comportamento do órgão frente aos novos acontecimentos, bem como a permanência mais duradoura de determinados homens bons nos cargos da governança, parecem indicar uma estreita articulação entre esses indivíduos e a Coroa portuguesa. Os diversos títulos concedidos ao senado se traduziriam como um reconhecimento dessa representação.

Esta situação parece não ter sido particular do Rio de Janeiro. István Jancsó e João Paulo Pimenta anotaram que a instalação da Corte na América imprimiu fortes alterações nos procedimentos das elites em diversas partes do Brasil. A proximidade do centro do poder provocou uma forte adesão pelas possibilidades de participação na gestão da coisa pública propiciando um desequilibrio entre regiões até então integrantes do conjunto de capitanias vinculadas à Coroa. A significância dessa alteração foi potencializada com o estatuto de Reino ao Brasil que, se por um lado atestava sua importância no quadro dos domínios portugueses; por outro, proporcionou que interesses conflitantes entre europeus e americanos no interior da mesma nação portuguesa se intensificassem. A partir de então novos canais de negociação, de conflitos e de conformação das identidades políticas foram estabelecidos no momento em que se efetivava a solução luso-brasileira. ${ }^{14}$

As divergências quanto ao projeto de unificação do Reino português provocaram a declaração de independência do Brasil em 1822, aprofundando os conflitos no interior da monarquia constitucional. Em 25 de março de 1824, o Imperador outorgou a constituição política do Império após ter dissolvido a Assembléia Constituinte poucos meses antes. No preâmbulo do texto está consignado que os "povos deste Império" reunidos em suas respectivas câmaras havia jurado o projeto de Consti- 
GOUVÊA, Maria de Fátima Silva, 1998, op. cit., p. 324 (grifos da autora). A historiadora alerta para algumas lacunas nas listas consultadas que, todavia, não impediram estabelecer parâmetros mais gerais para avaliar o perfil dos "homens de governança".

\section{4}

JANCSÓ, István; PIMENTA, João Paulo Garrido. Peças de um mosaico (ou apontamentos para o estudo da emergência da identidade nacional brasileira). In: MOTA, Carlos G. (Org.). Viagem Incompleta. A experiência brasileira (1500-2000). Formação: histórias. São Paulo: Senac, 2000. p. 127-175; Ver também, JANCSÓ, István, A construção dos Estados nacionais na América Latina: apontamentos para o estudo do Império como projeto. In: SZMRECÁNYI, Tamás; LAPA, José Roberto do Amaral. (Orgs.). História econômica da Independência e do Império. São Paulo: Hucitec; ABPHE;Edusp, 1996, p. 3-26; SLEMIAN, Andréa; PIMENTA, João Paulo G. 0 "nascimento político do Brasil". As origens do Estado e da nação (18081825). Rio de Janeiro: DP \& A, 2003.

15

Constituição Politica do Império. 1824. Brasilia: Minter, 1986, p. 17-39.

16

LYRA, Maria de Lourdes Viana. "Pátria do Cidadão": a concepção de pátria/nação em Frei Caneca. Revista Brasileira de História. São Paulo, Anpuh; Humanitas Publicações, v. 18, n. 36, 1998, p. 395-420.

17

Documento da municipalidade de Salvador relacionado com a Independência do Brasil, 18211823. Salvador: Departamento de Cultura/SMEC, 1972 , p. 147

18

Loc. cit.

19

ARMITAGE, John. História do Brasil. São Paulo: Ed. de São Paulo, 1914.

\section{0}

Coleção das leis do Império. Lei de $1^{\circ}$ de Outubro de 1828 , p. 560-571.

\section{1}

Das quais constavam: Pernambuco, Bahia, Rio de Janeiro, Minas e São Paulo; Pará, Maranhão, Ceará, Paraiba, Alagoas e Rio Grande do Sul teriam 28 e as demais 20. Número que poderia ser alterado por Lei Geral. Cf. artigo $2^{\circ}$ do Ato Adicional de 12 de agosto de 1834. Constituição politica do Império. 1824. Brasilia: Minter, 1986, p. 41-46.

\section{2}

DOLHNIKOFF, Mirian. Elites regionais e a construção do Estado Nacional. In: JANCSÓ, István (Org.) op. cit., p. 431-468. BANDECCHI, Brasil. 0 municipio no Brasil e sua função política. 4. ed. Revista. São Paulo, 1977. tuição, atendendo ao pedido de D. Pedro I para que assim procedessem. ${ }^{15}$ 0 registro sugere que a lei fundamental definidora das relações estruturantes do Império e da caracterização política de seus habitantes originava, ainda que outorgado, sob o assentimento dos "cidadãos brasileiros". Todavia, ao recorrer aos órgãos camarários para que manifestassem sobre o projeto, o imperante buscava recuperar a representação do poder local visando legitimar suas ações arbitrárias.

Ao que tudo indica, a ampla maioria das câmaras não se opôs ao projeto apesar do forte apelo de Frei Caneca contra o juramento do texto e da crítica veemente à carta em sua fala na câmara municipal de Recife. $^{16} 0$ senado da câmara de Salvador, por exemplo, em ata de 10 de fevereiro de 1824, após sugerir a reflexão do artigo 137 que estabelecia a vitaliciedade dos conselheiros de Estado ("qualidade sem dúvida contrária à natureza dos seus cargos") e sobre a caracterização das forças militares

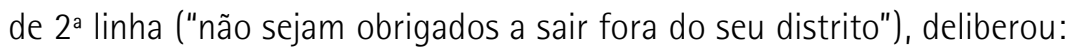
"10 Que se rogue a S.M. o Imperador que faça convocar o quanto antes, e em qualquer tempo o Corpo Legislativo na forma determinada no Projeto, que fica como constituição, dignando-se de desistir do propósito de reunir uma nova Assembléia Constituinte para o Império".17

$\mathrm{Na}$ opinião dos conselheiros, as eleições não teriam mais sentido com o juramento da constituição e, além disso, "com a repetição das eleições sentem os povos gravíssimos incômodos pelas grandes distâncias da província [...]".18 Para John Armitage, embora algumas municipalidades tenham objetado a criação do senado vitalício e contestado a separação do Poder Moderador do Executivo, a constituição foi plenamente aclamada. Entretanto, acredita que se o texto fosse submetido à sanção de uma nova assembléia constituinte, como fora prometido, provavelmente tais pontos seriam rejeitados. ${ }^{19}$

Em outubro de 1828 foi promulgada a lei definidora das atribuições dos órgãos camarários, bem como dos critérios para a eleição dos seus membros e dos juizes de paz. Certamente a principal alteração para as câmaras foi a retirada das suas funções judiciárias, definindo-as como "corporações meramente administrativas" (art. 24). Ademais, muitas das deliberações pela municipalidade deveriam ser encaminhadas ao Conselho Geral da Província, inclusive as posturas municipais, podendo ser alteradas ou revogadas pela representação provincial, conforme previa o artigo $72 .{ }^{20}$ Corroídos em sua autonomia, os poderes locais foram definitivamente absorvidos pelo poder provincial com a aprovação do Ato Adicional, de 12 de agosto de 1834, que procedeu algumas alterações e adições à constituição política do Império.

No âmbito das reformas, o Ato substituiu os Conselhos Gerais pelas Assembléias Legislativas Provinciais ampliando o número dos seus membros que variava de acordo a província. ${ }^{21}$ Mais do que isso, definiu amplas competências para as assembléias, inclusive a faculdade de criar e suprimir empregos municipais e provinciais, fixar ordenados, receitas e despesas, criar impostos e legislar "sobre a polícia e a economia municipal, precedendo propostas das câmaras" ( $\$ 4^{\circ}$, art. 10). Em decorrência, estabeleceu-se uma hierarquização entre governo da provincia e do município interferindo nas relações entre os grupos políticos locais e regionais. 22

Sérgio Buarque de Holanda atenta para as motivações dos homens que, inicialmente, retiraram do poder central o que parecia competir ao poder provincial para, em seguida, centralizar nas assembléias de província 
23

Apud HOLANDA, Sérgio Buarque de, op. cit., p. 25.

24

Sobre o processo de Independência do Brasil na Bahia, ver: CERQUEIRA E SILVA, Ignácio Accioli de. Memórias históricas e políticas da província da Bahia. Anotado por Braz do Amaral. Bahia: Imprensa Oficial do Estado, 1919-1931, v. 2-4; AMARAL, Braz do. História da Independência na Bahia. 2 ed. Salvador: Progresso, 1957; TAVARES, Luis Henrique Dias. História da Bahia. 10. ed. Salvador: Edufba;Unesp, 2001; ARAÚJ0, Ubiratan Castro de. A guerra da Bahia. Salvador: Ceao, 2001; SOUZA FILHO, Argemiro Ribeiro de, op. cit., GUERRA FILHO, Sérgio Armando, op. cit.; WISIAK, Thomas, op. cit., e Itinerário da Bahia na crise do Império luso-brasileiro (1821-1823). In: JANCSÓ, István (Org.). Independência: História e Historiografia. São Paulo: Hucitec, 2005, p. 447474.

25

Cf. WISIAK, Thomas, 2001, op. cit. Para uma dimensão do conflito envolvendo uma familia luso-brasileira, ver: FRANÇA, Antonio D'Oliveira Pinto da. Cartas baianas 1821-1824. São Paulo: Cia. Ed. Nacional; Rio de Janeiro: Núcleo Editorial da UERJ, 1980. o que era da alçada do município, justificando o questionamento do Visconde do Uruguai: "Não temos nas Províncias verdadeiras municipalidades. Foram entregues amarradas às Assembléias provinciais. Tem-se medo das câmaras municipais. Não se poderia com mais razão tê-lo das câmaras provinciais?".23

Assim, não se pode analisar as vicissitudes da estrutura políticoadministrativa na transição da América Portuguesa para o Império do Brasil sem vinculá-la à trama dos interesses que marcou o processo de construção da unidade nacional. Uma discussão que, se não é recente na historiografia, tem se revigorado a partir de novas perquirições sobre as alternativas políticas derivadas da crise da colonização na América e, nesse sentido, as disputas no interior das provincias evidenciam a dimensão política dos poderes locais e apontam outras questões para análise do problema nacional.

\section{Identidades políticas na Bahia no Primeiro Reinado}

A crise do Império luso-brasileiro provocou na Bahia profunda instabilidade contrapondo diferentes propostas de intervenção política na esteira dos acontecimentos propiciados pelo movimento constitucional. De fato, a guerra civil que eclodiu na região prolongou-se por pouco mais de um ano mobilizando homens de diferentes pontos da província em defesa do governo comandado pelo príncipe regente e contrário às tropas leais às Cortes portuguesas, na medida em que as possibilidades para a unidade do Império iam se reduzindo.

A posse do brigadeiro português Madeira de Melo no comando das armas da Bahia e a conseqüente intensificação da luta política motivaram a reação dos proprietários aglutinados na vila de Cachoeira, localizada no Recôncavo baiano. As estratégias de resistência se deram por meio da instalação do Conselho Interino, em 6 de setembro de 1822, que passou a disputar o controle político da província com a Junta de governo fixada em Salvador. As manifestações decorrentes desse quadro expõem a diversidade de interesses e projetos no interior da sociedade baiana com forte repercussão no processo de construção do novo Estado. 24

Uma das questões que divide a historiografia sobre a independência do Brasil na Bahia se refere à mudança de posicionamento das forças políticas da província que inicialmente apoiaram as Cortes portuguesas para, tempos depois, aderirem ao movimento de Independência em curso no Rio de Janeiro. Como demonstrou Thomas Wisiak, boa parte desses estudos centraliza a análise dos conflitos na polarização entre brasileiros e portugueses vistos como pólos opostos na defesa de seus interesses identitários. ${ }^{25}$ Esta interpretação simplifica a análise sobre a dimensão da luta política que se processou no interior da província e não ajuda a compreender os momentos de tensão, ruptura e de articulação das forças políticas em suas próprias relações e numa perspectiva de maior abrangência.

Parece evidente que a instabilidade política se agravou na medida em que as propostas aprovadas nas Cortes eram lidas como um claro intento de "recolonização" do Brasil, remetendo para um novo campo de ação que conformava um projeto de independência. É sintomático que a posição da junta provisória de governo nos primeiros meses de 1822 , instalada em Salvador, lamenta a nomeação do governador das armas que "acendendo entre nós o facho da discórdia, fez correr infelizmente o sangue de nossos irmãos", e clama ao rei providências para prevenir a 
Citado por CERQUEIRA E SILVA, Ignácio Accioli de. Memórias Históricas e Politicas da Provincia da Bahia. Bahia: Imprensa Oficial do Estado, 1931, p. 323 (nota 37)

\section{7}

As Juntas Governativas e a Independência. Rio de Janeiro: Arquivo Nacional; Conselho Nacional de Cultura, 1973, p. 804.

28

Sobre algumas indagações nesse sentido, ver: BERNARDES, Denis Antônio. Pernambuco e sua área de influência: um território em transformação (1780-1824). In: JANCSÓ, István (Org.) Independência: História e Historiografia. São Paulo: Hucitec, 2005, p. 379-410.

29

SOUZA FILHO, Argemiro Ribeiro de, op. cit. 0 autor analisa o processo de organização do Conselho Interino em Cachoeira, evidenciando que a resistência aos portugueses não se deu apenas pela mobilização do Recôncavo, conforme assinala a historiografia sobre o tema, mas teve um envolvimento fundamental das vilas interioranas da Bahia seja por meio do envio de homens para integrar o Exército Pacificador, seja contribuindo com as doações de gêneros alimentícios, dinheiro, algodão, requisitados pelo Conselho.

30

Sobre esses confrontos no Alto Sertão da Bahia, ver: SOUZA FILHO, Argemiro Ribeiro de, op. cit. Analisando a distribuição da riqueza em Salvador entre os anos de 1800-1850, com base em 395 inventários e testamentos, João Reis estima que os $10 \%$ mais ricos controlavam $67 \%$ da riqueza enquanto que os 30\% mais pobres apareciam como proprietários de apenas 1,1\%. Cf. REIS, João José. Rebelião escrava no Brasil. A história do levante dos malês em 1835. Edição revista e ampliada. São Paulo: Companhia das Letras, 2003 (especialmente parte I: Sociedade, economia, rebeliões na época dos malês).

31

LYRA, Maria de Lourdes Viana, op. cit., p. 415.

32

Cf. REIS, João José. A elite baiana face os movimentos sociais, Bahia (1824-1840). Revista de História, São Paulo, v. LIV, n. 108, 1976, p. 341384 e do mesmo autor Rebelião escrava no Brasil. A história do levante dos malês em 1835, op. cit.

33

DOLHNIKOFF, Mirian. Construindo o Brasil: unidade nacional e pacto federativo nos projetos das elites (1820-1842). Universidade de São Paulo, Tese de Doutorado, 2000. reprodução de cenas "verdadeiramente monstruosas entre Portugueses, em cujas veias giram o mesmo sangue". 26 Diferentes são os termos utilizados pelo governo provisório de Cachoeira, meses depois, em variados bandos que visam mobilizar homens para as forças de resistência: "0 Conselho [...] faz saber a todos os verdadeiros Patriotas amigos da Santa Causa da Independência Brasiliense que defendemos, e que quiserem decididamente mostrar ao Público até onde vai o apuro do seu Patriotismo, se apresentem [...] a unir-se com os Valorosos Defensores da Pátria conjuntamente com eles consigam os imortais Louros da Vitória, que esperamos obter contra nossos cruéis inimigos".27 Isto indica que mudanças significativas ocorreram nas intervenções das forças políticas da província sugerindo o aprofundamento da natureza dos projetos de Estado e Nação com relevo para a dinâmica dos poderes locais. ${ }^{28}$

Em meio à guerra civil, o Conselho Interino procurou mobilizar a população da província baiana orientando sobretudo as câmaras para arregimentar homens, obter munição e mantimentos destinados à sustentação do conflito militar. ${ }^{29}$ Todavia, as experiências políticas acumuladas potencializaram as diferenças entre os habitantes, indicando que as condições estavam longe de apontar para uma coesão politica. No interior, os conflitos políticos tomaram proporções ampliadas à medida que envolvia setores da população livre pobre, conferindo maior peso à questão das identidades. Além disso, a constituição de juntas provisórias nas vilas de Rio de Contas e Caetité, no alto sertão da Bahia, desencadeando um conflito aberto com as autoridades de Cachoeira, apontam para uma efervescência política que assolou a Bahia nos anos que se seguiram a crise do Império luso-brasileiro. ${ }^{30}$

A documentação produzida pelo Conselho Interino da Bahia informa como os protagonistas desses acontecimentos perceberam a crise das estruturas de poder e as perspectivas para a sua superação. Em variados momentos, o apelo ao sentimento patriótico ressalta a importância da defesa dos interesses comuns em situações de conflito da pátria. A falência de um modelo emancipador com base na "nação luso-brasílica" remetia para a construção da "nação brasiliense" implicando "no esforço renovado de identificação dos cidadãos-membros no novo Estado-Nação a ser constituido". 31 A conformação desse novo pacto político revela que os conflitos não se encerraram com o desfecho da guerra em julho de 1823.

Com efeito, as décadas de 1820-1830 significaram para a Bahia um periodo de intensa agitação consoante aos reveses de uma crise da economia escravista. Em um levantamento preliminar incluindo apenas Salvador e o Recôncavo registra-se, entre os anos de 1824 e 1838, a ocorrência de revoltas, motins, rebeliões, manifestações protagonizados por civis livres, soldados, escravos e libertos, a cada ano, evidenciando um cenário de crescente tensão e instabilidade. 32 É possível supor que esse quadro social, econômico e político da Bahia repercutiu na tomada de decisões dos grupos políticos que articularam o controle da província no processo de emergência do Estado nacional.

Mirian Dolhnikoff defende que as provincias regionais se aliaram à proposta de unidade capitaneada pelo Centro-Sul somente quando as elites tiveram garantido a autonomia regional para que pudessem conduzir seus projetos políticos e econômicos sem o controle excessivo do governo central. ${ }^{33}$ A sustentação dessa tese implica em questionar uma 
significativa parcela da historiografia que diferencia a atuação das elites no processo de construção do Estado nacional em regionais e, portanto, localistas, daquelas instaladas no governo central e que buscaram estabelecer uma hegemonia sobre as demais.

De fato, o estudo do ordenamento político das províncias a partir do desmoronamento das estruturas do Antigo Regime no Império Português deve considerar as diversidades locais e regionais e os embates politicos estabelecidos no interior dos grupos políticos que, em variados momentos e ao longo das primeiras décadas do Brasil Imperial, sacudiram a estabilidade política e exigiram intervenções dos poderes regional e central. Como essas diversidades se expressaram ante os referenciais políticos de unificação e que articulações foram estabelecidas para a preservação dos interesses provinciais, constituem o enfoque do nosso estudo sobre a Bahia nas primeiras décadas do oitocentos. 